\title{
Influence of argel (Solenostemma argel Del. Hayne) soil applications on flowering and yield of date palm (Phoenix dactylifera L.).
}

\author{
Tagelsir I. M. Idris, ${ }^{1}$ Asma M. A. Ibrahim, ${ }^{1}$ Elfatih M. Mahdi ${ }^{2}$ and Awad K.Taha ${ }^{3}$ \\ ${ }^{1}$ Department of Horticulture, Sudan University of Science and Technology. ${ }^{2}$ Department of \\ Horticulture, University of Khartoum. ${ }^{3}$ Department of Plant Protection, Sudan University of \\ Science and Technology.
}

\begin{abstract}
This study was conducted to investigate the influence of soil applications of argel (Solenostemma argel) dry leaves on flowering and yield of the dry date Barakawi cultivar in a completely randomized block design. Argel treatments were $0,37.5 \mathrm{~g}$ once (1X1), $37.5 \mathrm{~g}$ twice (1X2), $37.5 \mathrm{~g}$ thrice (1X3), $75 \mathrm{~g}$ once (2X1) and $112.5 \mathrm{~g}$ once (3X1). Each treatment was replicated 5 times in two successive seasons under the conditions of the Northern State, Sudan. Argel treatments enhanced flowering and yield parameters of date palms and improved the physical characteristics of the fruits. As a nutritional role seems invalid due to the low amounts used, gains from argel leaves additives might owe to either a pesticide or a growth regulator-like effect.
\end{abstract}

Keywords: Argel (Solenostemma argel Del. Hayne), Date palm (Phoenix dactylifera L.), Flowering, Yield.

\section{INTRODUCTION}

The date palm (Phoenix dactylifera) is one of the most important fruit trees in Sudan. The main producing area is the Northern State where dates constitute about $75 \%$ of the state's export. Sudan dates are mainly of the dry type (Nixon, 1969), which are easy to store and transport in a vast country with poor infrastructure for post harvest handling. For the last two decades, the date palms are attacked by a number of insect pests and diseases (Ahmed, 2007). The situation necessitates production and protection research efforts to increase yield (Idris et al., 2006).

Argel (Solenostemma argel) is a desert plant of traditional medical uses in the Sudan. It grows wild in the area extending from Dongola to Barber, particularly around Abu Hamad, where it is grown under irrigation (Elkamali and Khalid, 1996). Sudan is regarded as the richest source of this plant (Orange, 1982). Phyto-chemicals of medicinal properties from argel shoots had been reported by many workers (Roos et al., 1980; Kamel et al., 2000; Hamed, 2001). Sulieman et al. (2009) reported that the aqueous extracts of argel have antifungal and antibacterial properties.

The farmers in Kassala State put argel shoots in porous jute sacks in the irrigation canals to be leached by water. The water was effective in controlling aphids and white flies in summer tomatoes and Egyptian bull worm in okra respectively
(Unpublished observation). In a pilot field experiment on Brassica nigra, some peripheral plots were severely infested by aphids. The infestation caused stunting of shoots and delayed flowering compared to non-infected plots. However, upon treatment with argel as a soil additive, or a spray of shoot water extract or a combination of soil additive and spray, the vegetative growth was restored in all plots after pest disappearance and the plants flowered within 10-15 days after treatments. The inflorescence was abnormally thick and profusely branched in plants that received the combined treatment suggesting a growth-regulator-like effect and indicating the efficiency of argel as a pesticide (Abdelwahab, 2002).

Based on the these observations, this study was initiated with the objective of exploring the influence of additives of argel dry leaves to the soil on flowering and yield of Barakawi, the main dry date cultivar, under the conditions of the Northern State, Sudan.

\section{MATERIALS AND METHODS}

An experiment was conducted at Quoz Hindi area, Elgureir, Merawi Locality, Northern State, Sudan during 2004/2005 and 2005/2006 seasons. The date palm orchard was established in 1989, 2-3 kilometers away from the banks of the Nile. The sole cultivar was Barakawi which belongs to the group of dry dates. The soil is sandy loam. The orchard was irrigated by pump from the Nile and received no fertilizers except animal manure. The palms were 
mildly infested by insects and in some cases there were symptoms of diplodia infections.

Dry leaves of argel were added directly and incorporated into soil in a circle $7-10 \mathrm{~cm}$ deep, $30 \mathrm{~cm}$ away from the trunks of the palms. Then irrigation followed every two weeks. The argel treatments were control (no argel ), (37.5 g) added once on 24 November, i.e., $1 \times 1$, (37.5g) added twice on 24 November and 14 January, i.e., $1 \times 2$, (37.5g) added thrice on 24 November, 14 January and 28 February, i.e., $1 \times 3, \quad(75 \mathrm{~g})$ added once on 24 November, i.e., $2 \times 1$, (112.5g) added once on 24 November, i.e., $3 \times 1$.

In each treatment, 10 date palm trees were used, and each two were considered a replicate, i.e., 5 replicates per treatment in a randomized complete block design.

Data were collected at harvest time (15 September) on the following growth and yield parameters: number of bunches; number of spikes/bunch; fruit length $(\mathrm{cm})$; pulp thickness $(\mathrm{mm})$; bunches weight $(\mathrm{kg})$ and yield/palm $(\mathrm{kg})$.

The data were subjected to analysis of variance for the randomized complete block design, using MStatC computer program. Means were separated by Duncan's multiple range test at $\mathrm{P}=0.05$.

\section{RESULTS}

Analysis of the first season data showed that all argel treatments except the treatment of $1 \times 1$ significantly increased the number of bunches per palm compared to the control (Table 1) and the $3 \times 1,2 \times 1,1 \times 3$ and $1 \mathrm{X} 2$ performed similarly and gave the best results. In the second season the pattern of the first season was repeated but the best increase resulted from the treatments $1 \times 2,1 \times 3$ and $2 X 1$. It is noteworthy that the best treatment of the first season $(3 \times 1)$ ranked second in the second season.

Table 1. The effect of different additives of argel to soil on number of bunches/palm and number of spikes/bunch.

\begin{tabular}{|c|c|c|c|c|}
\hline \multirow[t]{2}{*}{ Treatments } & \multicolumn{2}{|c|}{ No. of bunches/palm } & \multicolumn{2}{|c|}{ No. of spikes/bunch } \\
\hline & Season 1 & Season 2 & Season 1 & Season 2 \\
\hline control & $11.1 \mathrm{c}$ & $11.7 c$ & $38.9 c$ & $49.6 c$ \\
\hline $37.5 \mathrm{~g}$ once & $13.5 b c$ & $12.2 \mathrm{bc}$ & $45.5 a b$ & $54.7 a$ \\
\hline $37.5 \mathrm{~g}$ twice & $14.2 a b$ & $14.0 a$ & $43.3 a b$ & $57.7 a$ \\
\hline $37.5 \mathrm{~g}$ thrice & $14.5 a b$. & $13.7 a$ & $44.2 a b$ & $52.4 b$ \\
\hline $75 \mathrm{~g}$ once & $15.3 a b$ & $13.9 a$ & $46.1 \mathrm{ab}$ & $48.8 c$ \\
\hline $112.5 \mathrm{~g}$ once & $16.2 a$ & $12.9 b$ & $48.2 a$ & $52.2 b$ \\
\hline CV\% & 18.9 & 4.4 & 10.4 & 5.9 \\
\hline
\end{tabular}

* No significant differences between means with the same letter(s) within column at $P=0.05$.

As for the number of spikes/ bunches the data of the first season showed that all argel treatments resulted in significant increase in the number of spikes/ bunch compared to the control (Table 1). A dose of $3 X 1$ was found best although it was not significantly different from treatments $2 \times 1$ and $1 \times 3$. However, in the second season, all argel treatments excelled the control except treatment $2 \times 1$. The performance of 1X1 and 1X2 was improved in this season as they ranked top. It is noteworthy that the best treatment in the first season came second.
The results of the effect of argel treatments on fruit length are presented in Table 2. In both seasons, treatment $2 \times 1$ ranked top for this parameter. However, only treatments $1 \times 3,2 \times 1$ and $3 \times 1$ resulted in significant increase in fruit length compared to the control in the first season. The increase in length resulting from all argel treatments was significant in the second season compared to the control. 
Table 2. The effect of different additives of argel to soil on fruit length and pulp thickness.

\begin{tabular}{|l|c|c|c|c|}
\hline Treatments & \multicolumn{2}{|c|}{ Fruit length (cm) } & \multicolumn{2}{c|}{ Pulp thickness (cm) } \\
\hline & Season 1 & Season 2 & $0.31 \mathrm{c}$ & $0.30 \mathrm{c}$ \\
\hline control & $4.6 \mathrm{~b}$ & $4.2 \mathrm{c}$ & $0.55 \mathrm{a}$ & $0.50 \mathrm{~b}$ \\
\hline $37.5 \mathrm{~g}$ once & $4.9 \mathrm{ab}$ & $5.1 \mathrm{a}$ & $0.50 \mathrm{ab}$ & $0.46 \mathrm{bc}$ \\
\hline $37.5 \mathrm{~g}$ twice & $4.9 \mathrm{ab}$ & $4.9 \mathrm{a}$ & $0.49 \mathrm{ab}$ & $0.48 \mathrm{~b}$ \\
\hline $37.5 \mathrm{~g}$ thrice & $5.2 \mathrm{a}$ & $4.7 \mathrm{~b}$ & $0.54 \mathrm{a}$ & $0.48 \mathrm{~b}$ \\
\hline $75 \mathrm{~g}$ once & $5.5 \mathrm{a}$ & $4.9 \mathrm{a}$ & $0.48 \mathrm{~b}$ & 8.3 \\
\hline $112.5 \mathrm{~g}$ once & $5.1 \mathrm{a}$ & $4.8 \mathrm{ab}$ & 16.18 & \\
\hline CV\% & 19.48 & 6.53 & & \\
\hline
\end{tabular}

* No significant differences between means with the same letter(s) within column at $\mathrm{P}=0.05$.

As shown in Table 2, the highest pulp thickness resulted from treatment $1 \times 2$ in both seasons. However all argel treatments increased pulp thickness. In the first season the highest values were obtained with treatments $1 \times 1$ and $2 \times 1$, while in the second season only treatment $1 \times 2$ ranked top with significant differences from all other treatments.

The influence of argel treatments on the mean weight of bunches is presented in Table 3. Treatments $1 \times 3$ and $3 \times 1$ scored the highest weights of bunch in the first season with significant difference from the control. In the second season treatment $1 \times 3$ also ranked top for bunch weight although the difference was not significant compared to all other argel treatments except the $1 \times 1$ treatment. Nevertheless, in this season all argel treatments resulted in highest bunch weights compared to the control.

All argel treated palms produced significantly higher yields in both seasons compared to the control (Fig. 1 ). The highest yield in the first season was obtained from treatments $3 \times 1$ and $1 X 3$. In the second season, the highest yield resulted from treatment $1 \times 3$ although it was not significantly different from treatments $2 X 1$ and $1 X 2$. However, in both seasons the lowest yield in argel treated palms resulted from treatment $1 \mathrm{X} 1$ although it was significantly higher than the yield of the control.

Table 3. The effect of different additives of argel to soil on weight of bunch.

\begin{tabular}{|l|c|c|}
\hline \multirow{2}{*}{ Treatments } & \multicolumn{2}{|c|}{ Bunch weight (kg) } \\
\cline { 2 - 3 } & Season (1) & Season (2) \\
\hline Control & $5.9 \mathrm{~b}$ & $6.7 \mathrm{c}$ \\
\hline $37.5 \mathrm{~g}$ once & $6.4 \mathrm{ab}$ & $6.6 \mathrm{ab}$ \\
\hline $37.5 \mathrm{~g}$ twice & $6.5 \mathrm{ab}$ & $6.9 \mathrm{a}$ \\
\hline $37.5 \mathrm{~g}$ thrice & $6.9 \mathrm{a}$ & $6.6 \mathrm{ab}$ \\
\hline $75 \mathrm{~g}$ once & $6.5 \mathrm{ab}$ & $6.5 \mathrm{ab}$ \\
\hline $112.5 \mathrm{~g}$ once & $7.1 \mathrm{a}$ & $5.68 \%$ \\
\hline $\mathrm{CV}$ & $17.48 \%$ & $\mathrm{a} \%$ \\
\hline
\end{tabular}

${ }^{*}$ No significant differences between means with the same letter(s) within column at $\mathrm{P}=0.05$. 


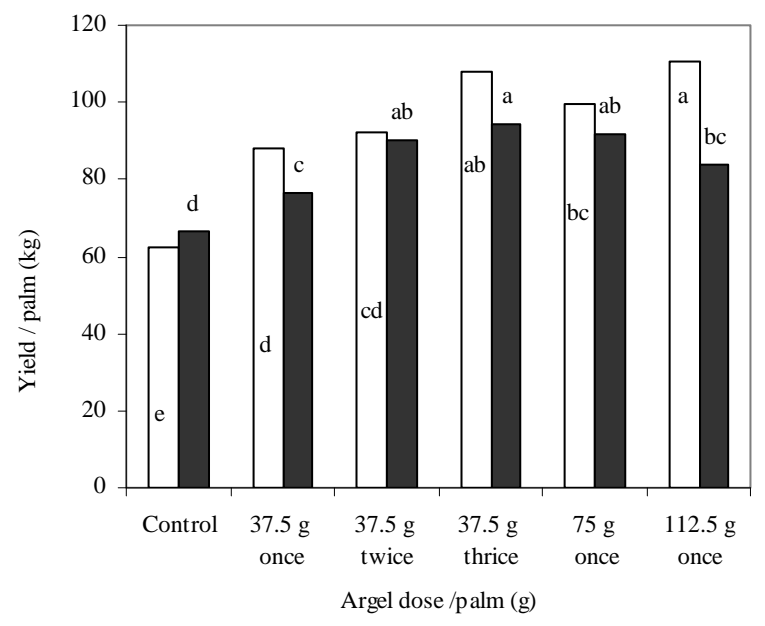

Fig. 1. The effect of different additives of argel to soil on yield /palm.

$\square$ season 1 ; a season 2

\section{DISCUSSION}

Beneficial effects were obtained from argel additive to the soil where the Barakawi date palm cultivar was planted. The yield almost doubled by an additive of $112.5 \mathrm{~g}$ of argel in the first season either in one or 3 split doses. However, compared to the control, all other treatments resulted in significant increases in yield in both seasons. The yield of 1X1 treatment was the lowest compared to the other argel treatments and this was an indication of inadequacy. In the second season, split doses seem more beneficial compared to the high single dose of $3 \times 1$. This indicated that the high doses in two successive seasons should be avoided because they cause a suppressive effect.

In addition to yield increment, a lengthy Barakawi fruit is a celebrity as it renders better returns. Considering this fact, the results showed clear increases in fruit length ranging between $0.4-1 \mathrm{~cm}$ in the first season and $0.5-0.9 \mathrm{~cm}$ in the second season. In both seasons the advantage of thicker edible part was an extra privilege. The overall argel benefits may owe to either of the following effects: an insecticidal effect as proposed by Sidahmed et al., (2009) who reported an insecticidal effect on white scale insects upon treatment of date palms with argel. Elkamali (2001) reported larvicidal effects of argel's crude aqueous extract against mosquito larvae. Moreover, an argel insecticidal effect on adult beetles of faba beans was reported by Bakhiet and Taha (2009). In this study, we observed a decline in termites and red ants populations after the treatments. In addition, antimicrobial effects as proposed by Elhady et al., (1994) and Sulieman et al., (2009) might have improved the health status of the palms. More-over, the speculation of a flowering promoting effect seems valid and fortified by the increments in number of bunches and spike length. A nutritive effect can not result from the low amounts of argel leaves used in this study. A date palm is normally fertilized by $20-40$ $\mathrm{kg}$ of farm yard manure in Sudan. Argel action seems to be systemic, absorbed by roots and translocated upwards where it imposes its effects on foliage and flowering initials. This assumption needs further biochemical studies to bio-assay the chemical constituents responsible for growth and flowering enhancements.

\section{CONCLUSION}

Significant yield gains were obtained in this study upon addition of low quantities of non-costly argel leaves to the soil of the date palms. The yield increment is of practical value for date palm growers in the Northern State. Beside the low cost, argel is a natural product devoid of safety hazards associated with synthetic pesticides, and its use is a step towards organic farming. This study attests a practical potential of argel which might be extended to other horticultural crops. As argel did not receive agronomic research attention, such a move might be needed in the near future.

\section{REFERENCES}

Abdelwahab, N. (2002). Response of black mustard (Brassica nigra) to phosphorous and nitrogen fertilizers. B.Sci. graduation project; Dept. of Hort., Sudan Univ. of Sci. and Technol., 2002. 53 pp.

Ahmed, M.A., (2007). The efficacy of four systemic insecticides using two methods of application against the green date palm pit scale insect (Asterolicanium phoenicis Rao) (Homoptera: Asterolicaniidae) in northern Sudan. Acta Horticulturae, 736: 369-389

Bakhiet, E.H. and Taha, A.K. (2009). Effects of leaves powder and aqueous extract of periwinkle (Vinca rosea L.) and hargal Solenostemma argel Del. Hayne on the adults of the faba bean beetle Bruchidius incarnates (Boh.) (Coleoptera: Bruchidae). J. Sci. \& Technol., 10(3): 116- 125.

Elhady, F.K.A., Hegazy, A.G., Ata, N. and Enabawy, M.L. (1994). Studies for determining antimicrobial activity of Solenostemma argel. Science J., 14: 138-145.

Elkamali, H. (2001). Larvicidal activity of crude aqueous extracts of Solenostemma argel (Del. Hayne) against 
mosquito larvae. J. of Herbs, Spices and Medicinal Plants, 8(4): 83-86.

Elkamali, H.H. and Khalid, S.A. (1996). The most common herbal remidies in Dongola province, Northern Sudan. Fitoterapia, 69: 118-121.

Hamed, A.I. (2001). New steroids from Solenostemma argel leaves. Fitoterapia, 72(7): 747-755.

Idris, T.I.M., Ibrahim, A.H. and Taha, A.K. (2006). A survey study on the growth, yield, pests and diseases of date palms in the Northern State, Sudan. Tech. Rept, Sudan Univ. of Sci. \& Technol. in collaboration with the Ministry of Agric. (Northern State), ARC and the University of Dongola. Sept.-Nov. 2006. 85 pp.

Kamel, M.S., Ohtani, K., Hasanain, H.A., Mohamed, H., Kasai, R. and Yamasaki, K.(2000). Monoterpene and pregnane glucosides from Solenostemma argel. Phytochemistry, 53(8): 937-940.

Nixon, R.W. (1969). Date culture in Sudan. Date Growers Institute Rept., 44: 4-19.
Orange, R.A. (1982). Ecological and phyto-chemical studies on Solenostemma argel growing in Saudi Arabia.. J. of the College of Science; King Saud University, 13 (1): 17-24.

Roos, S.A., Medgalla, S.E., Dishay, D.W. and Awad, A.H. (1980). Studies for determining antibiotic substances in some Egyptian plants: Screening for antimicrobial activities. Fitoterapia, 5: 303-308.

Sidahmed, O.A.A., Taha, A.K., Mardi, H.J. and Idris, T.I.M. (2009). The efficiency of spraying date palm trees with argel (Solenostemma argel Hayne) for the control of the white scale insect (Parlatoria blanchardii Targ.) (Homoptera, Diaspididae). J. Sci. \& Technol., 10(1): 142-149.

Sulieman, A.E., Elzobair, W.M. and Abdelrahim, A.M. (2009). Antimicrobial activity of the extract of Solenostemma argel plant. J. Sci. \& Technol., 10(3):104-115. 